\title{
Improving medical adherence and antithrombotic management for patients with chronic limb threatening ischaemia in Singapore
}

\begin{abstract}
Dear Editor,
Chronic limb threatening ischaemia (CLTI) represents the most advanced stage of peripheral artery disease (PAD), which, if left untreated, can progress to ulceration, gangrene, sepsis, major lower extremity amputation (LEA) and premature death. The prevalence of PAD ranges from $3 \%$ to $10 \%$ in the general population, increasing to $15-20 \%$ in people aged $\geq 70$ years. According to the 2015 report by the Organization for Economic Co-operation and Development, ${ }^{1}$ major LEA rates in Singapore are 2-3 times higher than those in Western countries, and are in fact the highest in the world. In Singapore, PAD patients are predominantly diabetic compared to PAD patients in Western populations (diabetes mellitus type 2, 90\% versus $50 \%$ ), younger at onset (50 vs 60 years), present with minimal claudication symptoms, and largely belowknee atherosclerotic occlusions (vs aorto-iliac-femoral disease), and more likely to have chronic renal failure $(50 \% \text { vs } 27 \%)^{2}$
\end{abstract}

The 1-year risk of major LEA in patients with CLTI exceeds $15-20 \%$ and the 5-year all-cause mortality rate is approximately $50 \% .^{3}$ As they have significant systemic atherosclerosis, patients with CLTI are at increased risk of premature death and have a higher incidence of cardiovascular (CV) events. ${ }^{4}$ Therefore, with a heightened risk of global atherothrombosis, systemic vascular prevention strategies are essential for the best holistic treatment. Current guidelines recommend antiplatelet monotherapy for prevention of $\mathrm{CV}$ events with a class IA recommendation for aspirin or clopidogrel, based on results of large CV outcome trials. In contrast, dual antiplatelet therapy combining aspirin and clopidogrel is used after interventionregardless of surgical or endovascular revascularisation for the reduction of post-procedural complications. It was given a class IIa, level $\mathrm{C}$ recommendation in the absence of any randomised data to support this indication. ${ }^{5}$ A recent rapid review in the Annals by our group suggested adherence to evidence-based medical treatment is extremely variable and that undertreatment is common in the PAD setting. ${ }^{6}$ Furthermore, data from Asian countries on this front are lacking.

Our institution, the Singapore General Hospital, a tertiary vascular centre that performs over 900 lower limb endovascular revascularisation procedures annually, currently sends its lower limb angioplasty data to the US Vascular Quality Initiative (VQI) ${ }^{7}$ database and is the only participating centre from the Asia-Pacific region. Our aim is to improve the quality of our lower limb angioplasty outcomes by collating our data to allow valid comparison and benchmarking to other global centres of excellence. VQI is a network of vascular specialists seeking to improve the quality and safety of vascular care by sharing data. Consent to collect, analyse and publish anonymised patient data was waived. Since subscribing in July 2019, we have logged 1,361 procedures $(1,016$ limbs, 873 patients and 2,749 lesions) as of May 2021. Table 1 shows the baseline demographics, which is notably significant.

Only $73 \%$ of patients were on an antiplatelet agent (APA) and $84 \%$ on lipid lowering therapy at presentation. Furthermore, considering that approximately $40 \%$ of patients had prior peripheral vascular intervention, only $51 / 345(15 \%)$ were on dual APA therapy. Potentially adjunct medical therapy plays an important role in minimising further limb and $\mathrm{CV}$ adverse events in what is a relentlessly progressive disease. In spite of this, best medical therapy is either being stopped or discontinued by the physician or patient at the primary and secondary level of outpatient specialist care. Valid reasons for non-adherence or discontinuation of these medications include symptoms such as muscle cramps or liver function derangement with statins, or bleeding complications and gastrointestinal upset with APA. Also, polypharmacy and altered physiological reserve increase the risk of adverse drug events in these frail and challenging patients. These latest Singapore data suggest we could do more to maximise adherence to existing PAD guidelines by trying to understand initially why a significant portion of our patients discontinue or are not put on best medical therapy.

It is also important to highlight that there may be a significant benefit for patients with PAD—both primarily and after revascularisation-in taking a combination of aspirin and low-dose rivaroxaban (rivaroxaban, a factor Xa inhibitor) to reduce first and subsequent adverse $\mathrm{CV}$ outcomes. There is emerging evidence that there is a fourfold risk of acute limb ischaemia and approximately $30 \%$ increased risk of 
Table 1. Patient demographics

\begin{tabular}{|c|c|c|}
\hline & $\begin{array}{l}\text { Number of patients } \\
\qquad(\mathrm{n}=873)\end{array}$ & $\begin{array}{l}\text { Percentage } \\
\quad(\%)\end{array}$ \\
\hline Mean age $\pm S D$, years & \multicolumn{2}{|c|}{$69.0 \pm 10.8$} \\
\hline Mean $\mathrm{BMI} \pm \mathrm{SD}, \mathrm{kg} / \mathrm{m}^{2}$ & \multicolumn{2}{|l|}{$24.6 \pm 4.6$} \\
\hline \multicolumn{3}{|l|}{ Sex } \\
\hline Male & 566 & 64.8 \\
\hline Female & 307 & 35.2 \\
\hline \multicolumn{3}{|l|}{ Ethnic group } \\
\hline Asian & 865 & 99.1 \\
\hline Caucasian & 4 & 0.5 \\
\hline Other & 4 & 0.5 \\
\hline \multicolumn{3}{|l|}{ Smoking status } \\
\hline Non-smoker & 496 & 56.8 \\
\hline Ex-smoker & 198 & 22.7 \\
\hline Smoker & 179 & 20.5 \\
\hline \multicolumn{3}{|l|}{ Comorbidities } \\
\hline Hypertension & 811 & 92.9 \\
\hline Diabetes & 732 & 83.8 \\
\hline Coronary artery disease & 512 & 58.6 \\
\hline Chronic kidney disease & 303 & 34.7 \\
\hline Cerebrovascular disease & 227 & 26.0 \\
\hline Dysrhythmia & 160 & 18.3 \\
\hline Congestive heart failure & 161 & 18.4 \\
\hline $\begin{array}{l}\text { Chronic obstructive pulmonary } \\
\text { disease }\end{array}$ & 27 & 3.1 \\
\hline \multicolumn{3}{|l|}{ Medication history } \\
\hline Statin & 736 & 84.3 \\
\hline Antiplatelets & 636 & 72.9 \\
\hline $\mathrm{ARB}$ & 396 & 45.4 \\
\hline Anticoagulants $^{\mathrm{a}}$ & 53 & 6.1 \\
\hline Insulin & 344 & 39.4 \\
\hline Non-insulin medication & 388 & 44.4 \\
\hline \multicolumn{3}{|l|}{ Ambulation } \\
\hline Ambulatory & 406 & 46.5 \\
\hline Ambulatory with assistance & 301 & 34.5 \\
\hline Wheelchair-bound & 157 & 18.0 \\
\hline Bedridden & 9 & 1.0 \\
\hline
\end{tabular}

Table 1. Patient demographics (Cont'd)

\begin{tabular}{lcc}
\hline & $\begin{array}{c}\text { Number of patients } \\
(\mathrm{n}=873)\end{array}$ & $\begin{array}{c}\text { Percentage } \\
(\%)\end{array}$ \\
\hline Prior interventions & & 39.5 \\
\hline $\begin{array}{l}\text { Leg arterial bypass/ } \\
\text { endarterectomy/PVI }\end{array}$ & 221 & 25.3 \\
$\begin{array}{l}\text { Percutaneous coronary } \\
\text { intervention }\end{array}$ & 169 & 19.4 \\
\hline $\begin{array}{l}\text { Coronary artery bypass graft } \\
\text { Number of limbs } \\
(\mathrm{n}=1016)\end{array}$ & $\begin{array}{c}\text { Percentage } \\
(\%)\end{array}$ \\
\hline Urgency & & 58.9 \\
\hline Emergency & 598 & 41.1 \\
\hline Elective & 418 & \\
\hline
\end{tabular}

ACE: angiotensin-converting enzyme; ARB: angiotensin receptor blocker; BMI: body mass index; PVI: peripheral vascular intervention; SD: standard deviation

${ }^{a}$ Comprising all types of anticoagulants including rivaroxaban

myocardial infarction in patients who have previously undergone a lower extremity revascularisation procedure. ${ }^{8}$ Therefore, the need for peripheral revascularisation identifies a PAD subpopulation to be at a heightened risk of future vascular ischaemic events. The Vascular Outcomes studY of ASA (acetylsalicylic acid) alonG with rivaroxaban in Endovascular or surgical limb Revascularisation for Peripheral Artery Disease (VOYAGER PAD) study was initiated to evaluate the efficacy and safety of low dose rivaroxaban $(2.5 \mathrm{mg}$ PO $\mathrm{BD})$ used together with aspirin in high-risk PAD patients undergoing lower extremity revascularisation. ${ }^{9}$

This landmark study enrolled 6,564 patients in 34 countries who had PAD and had undergone lower extremity revascularisation. Patients were randomly assigned to receive either rivaroxaban or a placebo, in addition to daily aspirin. There was a $15 \%$ significant relative risk reduction of developing a first major adverse limb or $\mathrm{CV}$ event in patients who received rivaroxaban compared to those who received placebo, seen as early as at 3 months, with a continued effect through to 3 years follow-up. Rates of the principal safety outcome of major bleeding increased but were not significantly different between the 2 groups $(2.7 \%$ vs $1.9 \% ; P=0.07)$. During 3 years of follow-up, approximately a third of patients had a CV event, in spite of high utilisation of background medical therapy. ${ }^{10}$

However, there was an absolute risk reduction of $12.5 \%$ in those receiving low dose rivaroxaban, which 
is a big advantage in avoiding the need for patients to be admitted for treatment of vascular complication. From our VQI database to date, only $17 / 873$ (1.9\%) were placed on the low dose rivaroxaban regimen following revascularisation. Cost and access to the low dose formulation may be limiting factors currently, but snapshots from the current data suggest we could do more to improve not only medical adherence to traditional APA therapy, but also start a low dose thrombin inhibitor to prevent future $\mathrm{CV}$ events and reduce the number of major LEAs.

\section{REFERENCES}

1. OECD. Cardiovascular Disease and Diabetes: Policies for Better Health and Quality of Care. OECD Health Policy Studies. Paris: OECD Publishing; 2015.

2. Tay WL, Chong TT, Chan SL, et al. Two-year clinical outcomes following lower limb endovascular revascularisation for chronic limb threatening ischaemia at a tertiary Asian vascular centre in Singapore. Singapore Med J 2020:1-25.

3. Duff S, Mafilios MS, Bhounsule P, et al. The burden of critical limb ischemia: a review of recent literature. Vasc Health Risk Manag 2019;15:187-208.

4. Davies MG. Criticial limb ischemia: epidemiology. Methodist DeBakey Cardiovasc J 2012;8:10-4.

5. Aboyans V, Ricco JB, Bartelink MEL, et al. 2017 ESC Guidelines on the Diagnosis and Treatment of Peripheral Arterial Diseases, in collaboration with the European Society for Vascular Surgery (ESVS): Document covering atherosclerotic disease of extracranial carotid and vertebral, mesenteric, renal, upper and lower extremity arteries. Endorsed by: the European Stroke Organization (ESO) The Task Force for the Diagnosis and Treatment of Peripheral Arterial Diseases of the European Society of Cardiology (ESC) and of the European Society for Vascular Surgery (ESVS). Eur Heart J 2018;39:763-816.
6. Chan SL, Rajesh R, Tang TY. Evidence-based medical treatment of peripheral arterial disease: A rapid review. Ann Acad Med Singap 2021;50:411-24.

7. Society for Vascular Surgery. Patient Safety Organization, Vascular Quality Initiative. Available at: https://vascular.org/research-quality/ vascular-quality-initiative/patient-safety-organization. Accessed on 9 April 2020.

8. Bonaca MP, Gutierrez JA, Creager MA, et al. Acute Limb Ischemia and Outcomes With Vorapaxar in Patients With Peripheral Artery Disease: Results From the Trial to Assess the Effects of V orapaxar in Preventing Heart Attack and Stroke in Patients With Atherosclerosis-Thrombolysis in Myocardial Infarction 50 (TRA2 degrees P-TIMI 50). Circulation 2016;133:997-1005.

9. Bonaca MP, Bauersachs RM, Anand SS, et al. Rivaroxaban in Peripheral Artery Disease after Revascularization. N Engl J Med 2020;382:1994-2004.

10. Bauersachs RM, Szarek M, Brodmann M, et al. Total Ischemic Event Reduction with Rivaroxaban after Peripheral Arterial Revascularization in the VOYAGER PAD Trial. J Am Coll Cardiol 2021;78:317-26.

Tjun Yip Tang ${ }^{1}$ FRCS, Ankur Patel ${ }^{2}$ FRCR, Shereen Xue Yun $\underline{\text { Soon }}{ }^{1}{ }_{B S c}$, Sze Ling $\underline{\text { Chan }}{ }^{3} P h D$, Charyl Jia Qi Yap ${ }_{B S C}^{1}$, Sivanathan $\underline{\text { Chandramohan }}{ }^{2} F R C R$, Tze Tec Chong ${ }^{1}$ FACS

${ }^{1}$ Department of Vascular Surgery, Singapore General Hospital, Singapore ${ }^{2}$ Department of Vascular Interventional Radiology, Singapore General Hospital, Singapore

${ }^{3}$ Health Services Research Centre, SingHealth, Singapore

Correspondence: Prof Tjun Yip Tang, Department of Vascular Surgery, Singapore General Hospital, Level 5 Academia Building, 20 College Road, Singapore 169856 .

Email: tang.tjun.yip@singhealth.com.sg 